\title{
GROWTH FORMS OF LARGE FROST CRYSTALS IN THE ANTARCTIC
}

\author{
By C. A. KNIGHT
}

(National Center for Atmospheric Research, Boulder, Colorado 80302, U.S.A.)

and A. L. DEVRIES

(Department of Physiology and Biophysics, University of Illinois, Urbana, Illinois 61801, U.S.A.)

\begin{abstract}
A variety of frost-crystal forms found growing from the vapor in ice caves and tunnels in the Antarctic are described and illustrated. Complex layered structures found within large, skeletal crystals are ascribed to the action of the temperature gradient. Some novel $c$-axis growth forms and a rare type of bicrystal growth - accelerated growth in a particular direction along a particular grain boundary - are also shown.

RÉsumé. Formes de croissance des grands cristaux de givre en Antarctide. Description de différentes formes de cristaux de givre rencontrés dans des grottes et tunnels antarctiques. Les structures litées complexes que montrent les grands cristaux squelettiques sont attribuées à l'effet d'un gradient de temperature. On décrit également des formes de croissances originales par rapport à l'axe
\end{abstract}

\section{INTRODUCTION}

Many visitors to the Antarctic and other cold glacierized places have admired the huge frost crystals that grow from the vapor in ice caves and crevasses. One of the authors (A.L.D.) brought some back from the Antarctic in dry ice after the 1982-83 season and gave them to the other (C.A.K.) for study in a cold laboratory. Then in October and November 1983 both of us collected more of the crystals, observed as much as we could at their surroundings, and studied them further in a cold laboratory at McMurdo Station. Both the size and the beauty of these crystals are remarkable. Single crystals were as big as $0.5 \mathrm{~m}$ long, and the ice caves in which many of them grow are strikingly beautiful; being in them is like being inside a huge crystal chandelier. Somewhat to our surprise, however, there were several crystal forms that evidently have not been described before. Furthermore, a literature search reveals few detailed descriptions of frost crystals. Frost is so common that this also was surprising; though perhaps its very commonness is the explanation. This paper's objective is to describe the interesting features that were observed; several of the features are puzzling, at least to us, and we offer a very little speculative discussion about causes where it seems appropriate.

\section{HISTORICAL}

It is difficult to write about "new" observations of such a commonplace phenomenon as frost without uneasy feelings about the possibility of missing important references, especially from previous centuries. We rely on the apparently thoroughly researched book by Seligman (1980) which summarizes the then-current knowledge of snow, frost, and ice at the Earth's surface. In his classification, all the crystals described herein are forms of "crevasse hoar". Perhaps unfortunately, his terminology has not become common usage, and we will use the common word "frost", as generic for all ice that grows senaire (c) ainsi qu'un nouveau type de croissance d'un bicristal (croissance accelérée dans une direction particulière le long d'un joint de grain particulier).

ZUSAMMENFASSUNG. Reifkristalle in Wachstumsformen grosser Reifkristallformen, deren Wachstum aus dem Wasserdampf in Eishöhlen und Tunnels der Antarktis beobachtet wurde, wird beschrieben und abgebildet. Komplexe Schichtstrukturen, die innerhalb grosser, skelettartiger Kristalle gefunden wurde, lassen sich der Wirkung des Temperaturgradienten zuschreiben. Einige ungewöhnliche $c$-Achsen-Wachstrumsformen und ein neuer Typ des bikristallnen Wachstums - beschleunigtes Wachstum in einer bestimmten Richtung längs einer bestimmten Korngrenze - werden ebenfalls vorgeführt.

on a surface from supersaturated vapor. Large frost crystals are fairly common in crevasses in Alpine glaciers and in ice caves or tunnels in Greenland and the Antarctic. Seligman produced photographs and brief descriptions of skeletal crevasse-hoar crystals, and remarked on their similarity to depththoar crystals. (Depth hoar grows in a snow-pack, in response to diffusion of water vapor under the influence of a temperature gradient.) Seligman also reported the spiral, scroll-shaped forms that are illustrated below. LaChapelle (1969) contains good photographs of hoar frost and one of crevasse hoar within a temperate glacier, grown at very nearly $0^{\circ} \mathrm{C}$.

Nakaya (1935) noted close similarities between many natural frost forms observed at a mountain hut in Hokkaido and snow-crystal forms. (He called these crystals "rime", which is contrary to modern usage.) Nakaya and Sato (1935) then duplicated these forms in a convection chamber in the laboratory. They did not, however, systematically evaluate effects of external gradients. More recently, there has been a great deal of work on snow-crystal growth; both observation of natural crystals and laboratory investigation. Only brief mention of frost forms is made in a few of these studies, to our knowledge. Snow-crystal formation is both more important than frost and is a simpler phenomenon. While both grow by direct condensation of vapor, snow grows within a quite uniform environment, while frost crystals grow from a surface of some kind, almost necessarily in a superimposed gradient of temperature and/or supersaturation. Snow crystals cannot grow nearly as large as frost, of course, because they fall. In the laboratory, very small ones are in free fall, and somewhat larger ones can be grown in simple, vertical wind tunnels; or they can be given supported on very thin fibers. Snow-crystal growth forms are well studied, and they change in complex ways as a function of temperature especially, but also of supersaturation and ventilation.

There is no comprehensive, up-to-date summary of 
snow-crystal observations and research, but an interested reader can consult a recent text in cloud physics for entry into the literature. While obviously relevant to frost, we will not discuss snow-crystal growth in general.

Levi and Kobayashi (1967) did the only experimental work of which we are aware on the effect of gradients on the forms of ice single crystals. They studied very small crystals and observed the thin sheets and fibers that they leave behind as they migrate.

\section{ENVIRONMENTS OF THE CRYSTALS}

The crystals that are described here come from three locales.

The Erebus Glacier tongue is an arm of a glacier on the side of Mount Erebus, about $16 \mathrm{~km}$ from McMurdo, that extends out some $10 \mathrm{~km}$ from shore, floating on the ocean surface. (The end breaks of $f$ and floats away every several years.) Its width and the height of its surface above sea-level undulate, but nominal values are $2 \mathrm{~km}$ and $5 \mathrm{~m}$, respectively. Portions of crevasses (caves) below sea-level are flooded with sea-water, which produces flat floors in some of them. Others do not extend down to sea-level. The frost crystals grow on the ceilings and the upper parts of the walls of the caves, clearly in response to winter conditions, when the upper surface of the ice tongue cools to $-30^{\circ}$ to $-40^{\circ} \mathrm{C}$ while the ocean keeps the lower part of the ice tongue relatively warm. In late October 1983, the one cave most studied had a temperature gradient in the wall of about $0.3 \mathrm{deg} \mathrm{m} \mathrm{m}^{-1}$, colder upwards, at about $-17^{\circ} \mathrm{C}$. The largest crystals grow from the ceiling and the upper parts of the walls. The floor and lower walls usually show no crystal growth. Many of the best crystals grow from icicles. Photographs of the ensembles of crystals in the caves were taken, but no lighting technique was found that gave results suitable for reproduction here.

Obviously, the boundary conditions for the growth are ice saturation at the floor, walls, and ceiling of a cave, along with the temperature gradient. With the warmer temperatures at the floor, the air in the caves is unstable and convection currents undoubtedly help the crystals to grow to large sizes. That growth probably takes place within one season; within approximately 6 months or less. While we cannot prove this assertion, there is a lot of evidence of summer melt within the caves: icicles and rounded, instead of angular, ice blocks. In the ice cave near Scott Base, described below, an older, much-melted generation of frost crystals was clearly discernible "beneath" the fresh crystals. Growth rates of ice from the vapor measured in the laboratory are adequate to produce meter-sized ice crystals in several months in these circumstances.

The caves in the Erebus Glacier tongue were distinctly different in 1983 from their state in 1982 The ice was quite pure and the caves were dry in 1982 but, in 1983, salt water permeated the ice. Particularly after people had been in a cave for some time, salt water could be seen dripping of the frost crystals and any other projections. The crystals slowly, visibly disintegrated, though the temperature was still far below $0^{\circ} \mathrm{C}$. Probably a storm during the 1982-83 Antarctic summer thoroughly soaked the entire glacier tongue with salt spray. In spite of all the salt water, the skeletal growth forms of many of the crystals appeared perfectly sharp; not notably different from the previous year's crystals or, in general, from those in the ice cave near Scott Base.

The second locale was a small ice cave in a tiny glacier, just north-east of Scott Base, at the end of Hut Point Peninsula. The entrance to the cave was set in the ice foot about $2 \mathrm{~m}$ above the sea ice, just at the shore. The crystals again were on the upper walls and ceiling, and no salt was evident.

The third locale was in an abandoned tunnel some 6-8 m beneath the snow surface, at the "old" South Pole station. There was a copious growth of frost, on the ceiling primarily, in a few spots. The temperature there is quite constant year-around, at the mean annual temperature of nearly $-50^{\circ} \mathrm{C}$. It was not obvious why there was frost in some places but not others, and indeed one had to wonder why there was any frost at all, since at that depth in the snow the temperature gradients should be very small. The age of the crystals was indeterminable, and the tunnel had been abandoned for about eight years.

Two other locations with huge frost crystals were reported but the authors could not reach them: old old tunnels in the snow at Siple station and at the top of Mount Erebus on Ross Island, where the warm ground maintains large tunnels at the base of the snow. This latter sounded especially interesting, because there was a report of a distinct crystal habit change with height on the tunnel walls (personal communication from W. MacIntosh), and the situation is one in which Nature might produce high water-vapor supersaturations.

The conditions under which most of the crystals grew were probably neither constant nor uniform, and are certainly not well known. The purpose here is to describe a number of features that seem not to have been described before. We will not even refer to growth conditions except to note the locale of the illustrated crystals. To the extent that more exact formation conditions are interesting or important, laboratory studies would be the best way to determine them, and the present descriptions might help in the initial design of experiments. We divide the descriptions into two categories: the normal skeletal crystals and the unusual forms.

\section{SKELETAL GROWTH}

Skeletal growth of ice crystals has been observed in snow, and is shown schematically in Figure 1. This type of crystal growth is commonly recognized and well
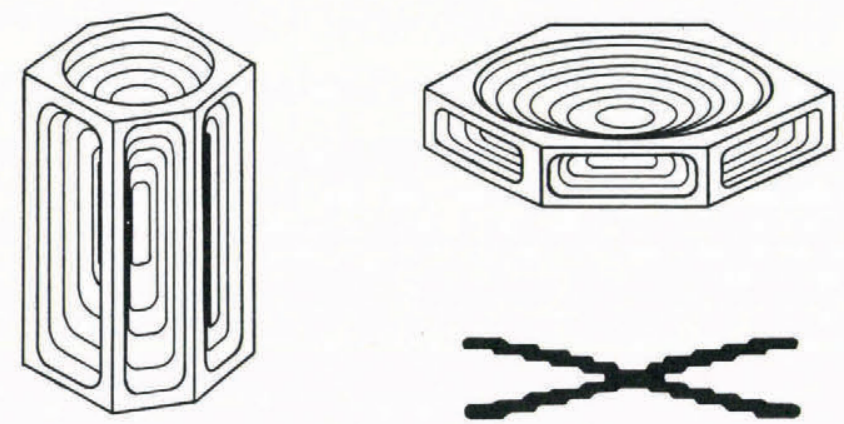

Fig. 1. Skeletal growth in a simple hexagonal form (after Mason and others, 1963). In the cross-section at lower right [0001] could be oriented left-right or up-down.

understood, and has been discussed perhaps most thoroughly by Frank $(1974,1982)$. At low enough supersaturation and small enough size, the crystal grows as a solid hexagonal prism whose axial ratio depends in part on the intrinsic growth rates of basal and prism faces. With increasing supersaturation or increasing size, the interaction of the diffusion field with the shape leads to "starvation" of the face centers. Eventually, nearly all growth occurs at the edges and corners, and skeletal structure (Fig. 1) is the result. One can easily imagine a next stage of this process, in which the centers of the edges also become starved, and eventually one might end up with corner growth only: twelve spikes at some angle between the $a$-axis and the $c$-axis. Free growth of ice in supercooled water exhibits this growth form (see e.g. Lindenmeyer and Chalmers, 1966). Hallett (1965) described vapor growth something like this at $-4{ }^{\circ} \mathrm{C}$ and very high supersaturation, and Kobayashi (1965) showed its occurrence at $-92^{\circ} \mathrm{C}$ and high supersaturation. Forms approaching this, but not attaining it, will be illustrated below.

Most of the frost crystals - far more than $99 \%$, in 
terms of area of coverage, number, or any other measure - in the Erebus cave and the Scott Base cave appear at first sight to be the ordinary skeletal variety. The axial length ratios vary, from about $1: 1$ to $1: 10(c: a)$, with values approaching the latter the more common. Figure 2 is a portion of a large, tabular crystal some $3 \mathrm{~cm}$ thick. Obviously, there are a lot more complex bifurcations in the internal structure than the idealized cross-section of Figure 1. Growth of the prism plane at the top of the figure was clearly faster than that of the other prism planes, and typically these crystals were oriented with the fastest growth more or less perpendicular from the walls or the ceiling. The extremely large crystals were all similar to that in Figure 2.

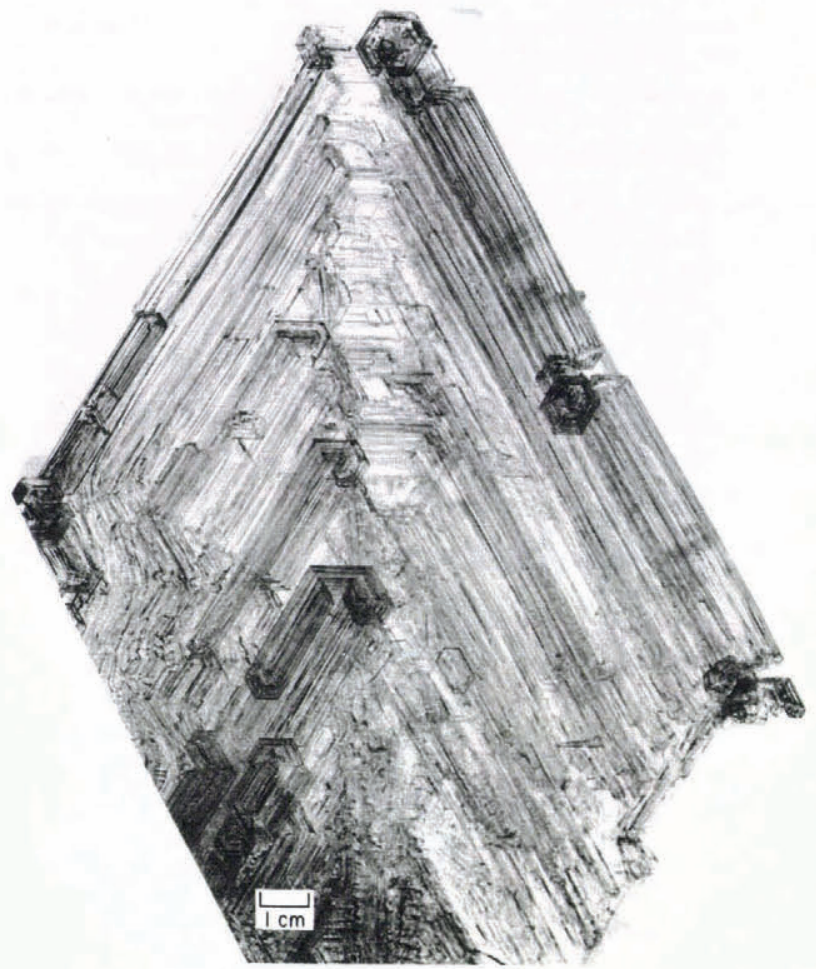

Fig. 2. Portion of a very large skeletal ice crystal from the Scott Base ice cave, some $3 \mathrm{~cm}$ thick, viewed parallel to [0001]. Bright-field, diffuse illumination.

Figure 3 shows a cup-shaped, skeletal crystal and a more complicated one. The orientation of (a) is obvious, and in (b) the $c$-axis is perpendicular to the long axis shown. Figures 2 and 3 already strongly suggest that the internal structure of even a simple-shaped skeleton is going to be much more complex than the simple stepped form shown in Figure 1.

The skeletal growths at the South Pole developed a distinctly different morphology, presumably because of either the very different temperature or different supersaturation, but the growth "principle" was the same. The crystals there were not as big as those near McMurdo. They did reach $10 \mathrm{~cm}$ in size, but were extremely fragile and all the photographs are of fragments of larger growths. The $c$-axis and $a$-axis growth rates in these crystals were approximately equal, but the growths appeared to be dominated much more by fast growth at the corners. As is shown in Figure 4a, the striated sheets that are left behind by edge growth still exist, but the corners branch in more complicated ways than was the case for the warmer crystals near McMurdo. Figure $4 \mathrm{~b}$ shows a crystal portion oriented with both the $c$-axis and an $a$-axis approximately within the plane of the photograph. Taking north toward the top, the $c$-axis extends north-east to south-west. The fundamental form is a hexagonal, tapering cup with [0001] along the cup axis. The major spine ( $\mathrm{N}-\mathrm{S}$ in Fig.
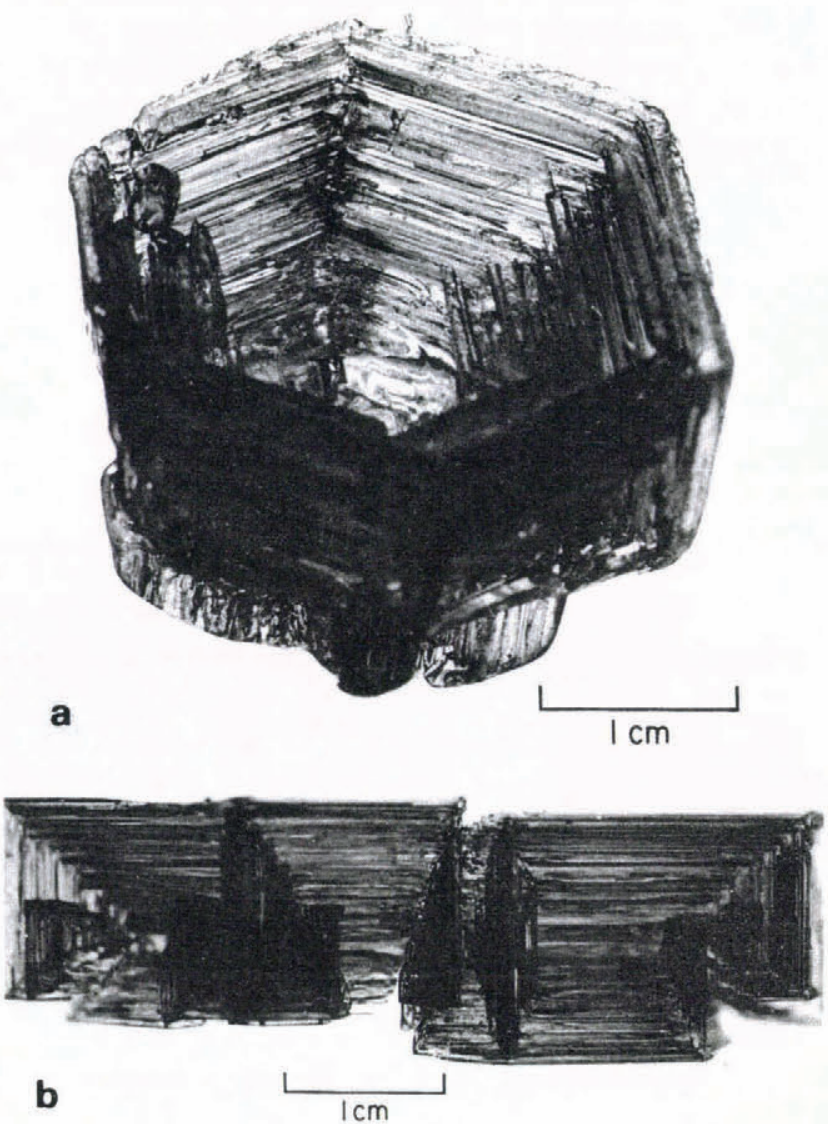

Fig. 3. a Cup-shaped skeletal crystal from the Erebus Glacier tongue, 1982. b. Skeletal crystal from the Erebus Glacier tongue, 1983, viewed perpendicular to [0001].

6) would have been one edge of a very large cup, but the cup (characteristically) is not completed: Instead, a series of smaller cups forms on the inside (the right) and there is a prominent "f in" of ice projections with well-developed prism and basal faces on the outside (the left). Note that these fins also occur along the outside edges of the smaller cups, seen to the right in Figure $4 \mathrm{~b}$. As can be seen in Figure 4c, these smaller "cups" are usually more complicated yet they are usually spiral, scroll-like forms.

\section{The spirals}

These spiral, or scroll forms have been noted by many observers, and they were of ten developed to a spectacular degree in the skeletal crystals. Figure 5 is a tracing of a thin section, cut perpendicular to [0001], through one of the largest spiral complexes observed. The spirals usually come in pairs and their formation is shown schematically in Figure 6. They start when one edge of a tapering, hexagonal cup fails to grow as fast at its center as it does at its two ends. The edge which develops the notch is typically the longest edge. (The hexagonal shape is usually distorted, presumably from an asymmetry of the field of supersaturation.) As the edge of the cup grows, the notch widens and eventually each edge turns inwards $120^{\circ}$. With further growth, the whole pattern expands at a rate that depends upon the growth direction - the angle $\alpha$ in Figure $6-$ and further $120^{\circ}$ inward turns occur, forming the spirals. Frank (1982) illustrated the spiral formation at the end of a straight column, with $\alpha=90^{\circ}$. Sometimes only one spiral develops well because the other gets "shadowed" by other growth, and loses its vapor supply. Spirals with $\alpha$ ranging from only about $20^{\circ}$ to nearly $90^{\circ}$ were seen, and in size they range from tiny snow crystals (see e.g. 

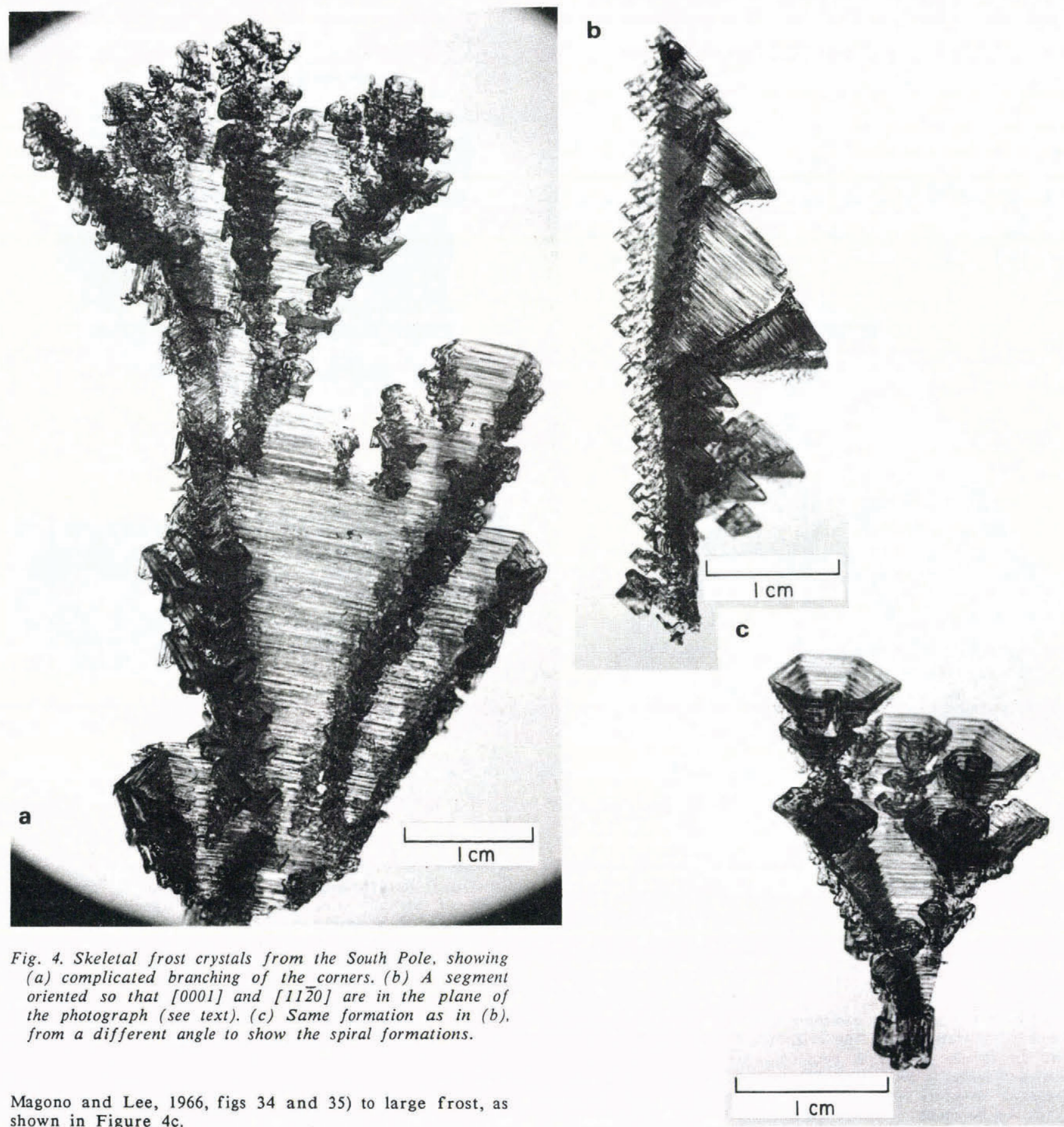

Magono and Lee, 1966, figs 34 and 35 ) to large frost, as shown in Figure 4c.

No discussions of why these spiral forms occur have come to our attention. Presumably they are a response to the spatial gradients of supersaturation produced by the growing crystals themselves. While this intuitively reasonable explanation is simple in principle, it might be very difficult to demonstrate in detail for this complex shape, and we do not follow this question further.

\section{Internal structure of the skeletal crystals}

Inspection of the skeletal crystals revealed that their internal structure of ten was far more complicated than that suggested by the schematic cross-section in Figure 1. In fact, complete, thin, basal sheets of ice were sometimes seen covering the hexagonal opening of a large skeletal specimen. It was very hard to observe the details of the internal shape in the transparent crystals directly, though in some examples the crystals gave the appearance of having a series of internal, projecting basal and prism sheets. Figure 3a suggests this strongly but it is hard to be sure.

In order to examine the internal structure, crystals

were cast in liquid diethyl phthalate (or dimethyl phthalate - either works*) at about $-5^{\circ} \mathrm{C}$ (the melting point), then the diethyl phthalate itself was frozen, and sections could be cut through the now-solid block without major disruption of the delicate internal structures. Figure 7 contains tracings of sections of portions of skeletal crystals parallel and perpendicular to [0001]. The suspected internal structure of thin shelves, rather than just internal steps, is confirmed. The shelves tend to be parallel to the basal and prism faces of the ice, but the crystallographic control is of ten notably imprecise. Figure 7c is another section parallel to [0001] of a larger crystal with coarser internal structure, which

*This method was learned from the Swiss avalanche research group at Davos, about 20 years ago. We are not aware of a formal reference. 


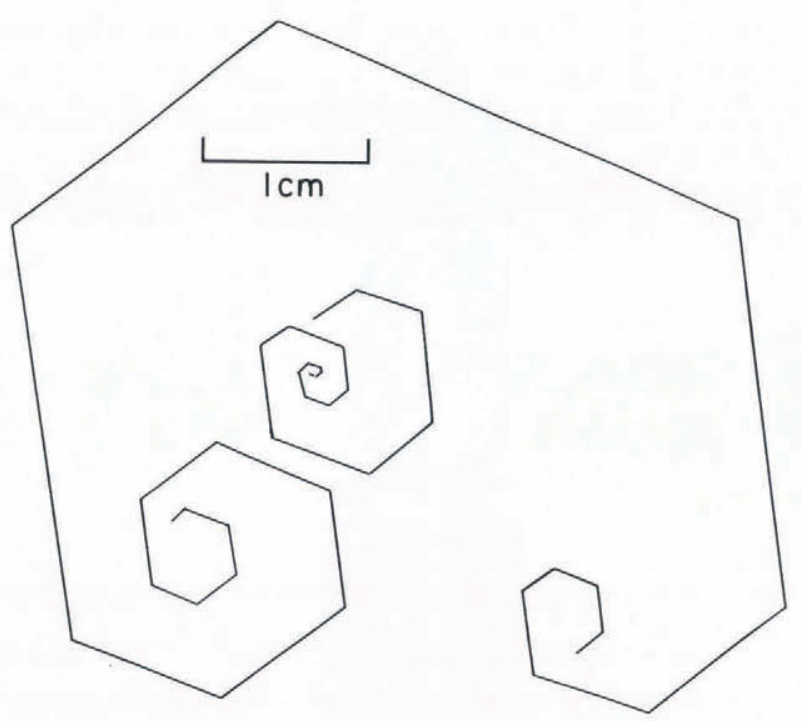

Fig. 5. Tracing of a large spiral complex from a crystal from the Scott Base ice cave.

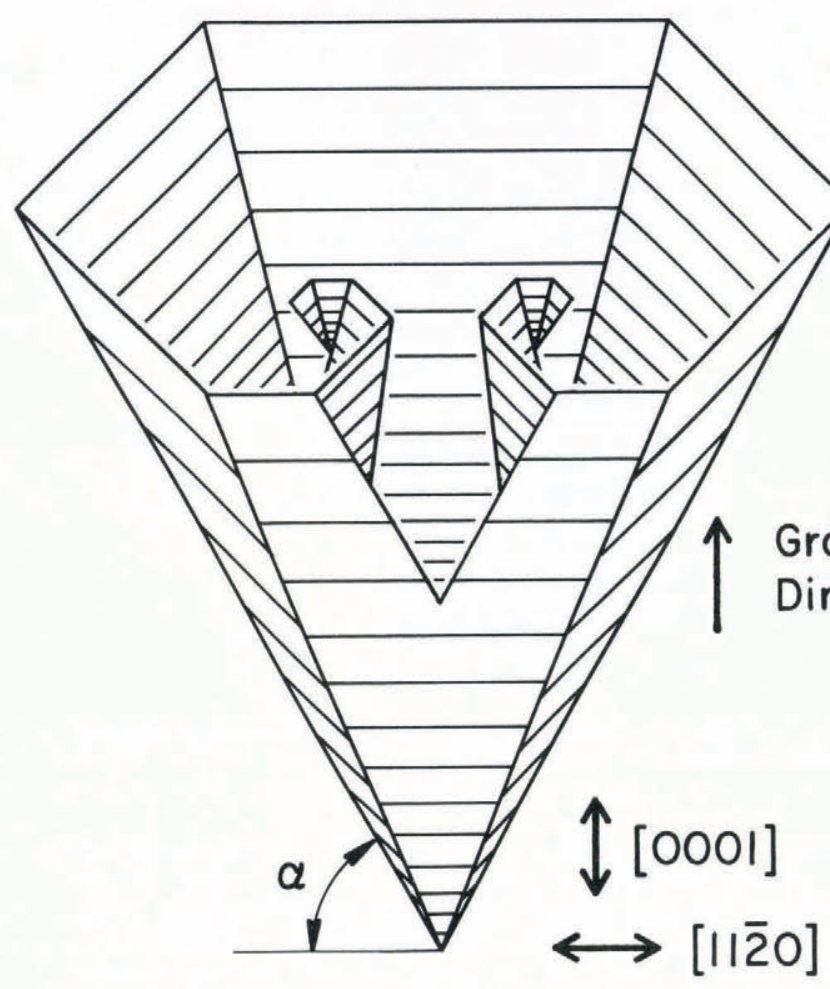

Fig. 6. Schematic view of an ideal spiral pair, seen in perspective.

shows an example of a complete sheet of ice across the basal opening.

One question to be asked is why these internal sheets of ice form at all. While we do not have a detailed answer to this question, temperature gradients are most probably the root cause. With convection occurring in the caves, the air in the upper parts of the tunnels is warmer than the walls. The giant frost crystals extend from the walls into the air and must themselves be a major (if not the major) conduit for the heat of condensation to be conducted back to the walls There are three paths for this: conduction in the ice, conduction and convection in the vapor, and "hand-to-hand" evaporation and condensation along the temperature gradient. This last mechanism is familiar to

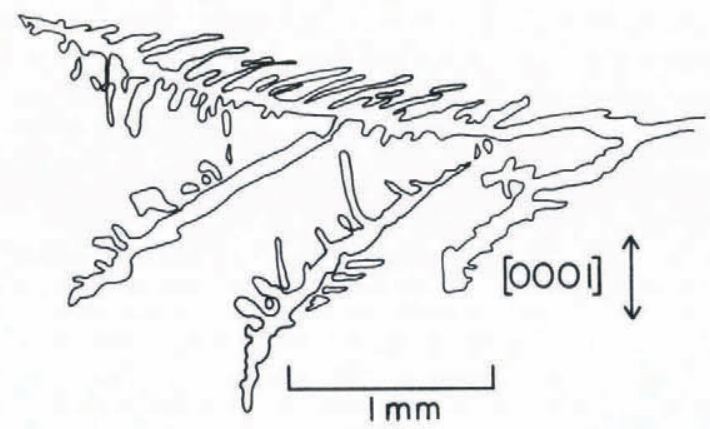

(a)

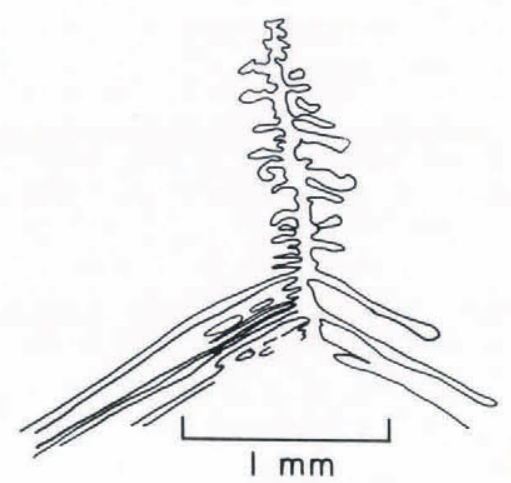

(b)

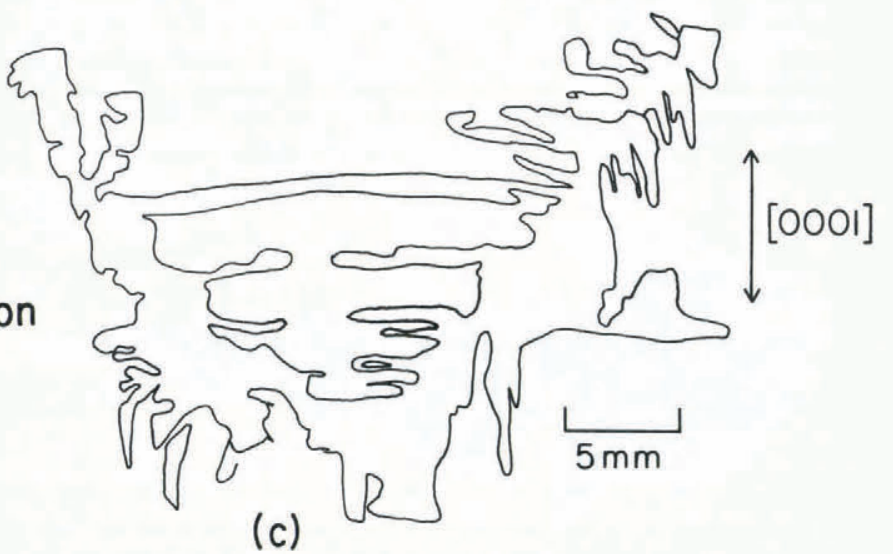

Fig. 7. Tracings showing the typical internal structures of large skeletal crystals, made from photographs of thin sections parallel (a) and perpendicular (b) to [0001]; Scott Base ice cave. (c) Section through a large, hexagonal cup (cf. Fig. 3a), parallel to [0001]. Erebus Glacier tongue, 1982.

students of depth-hoar formation in snow (see e.g., recently, Colbeck, 1983, and Sommerfeld, 1983). When the ice is finely divided, as in snow on the ground, a major mechanism of heat flow (and, of course, of metamorphism of the snow itself) is evaporation on the sides of grains facing the cold end of the gradient and condensation on the opposite sides. In our case the whole process is taking place within crystals of complicated shape, and is most probably the major reason for the complicated shapes in the first place. In this view, the sheets of ice within the crystals are actually migrating out away from the cave wall or ceiling within their parent crystals, by this evaporation-condensation process.

It is beyond our intended scope to speculate much 
further on this process, except to note that it has received little or no discussion in the literature on crystal growth, though Nakaya (1954) illustrated an early stage of formation of these sheets in artificial frost in his figures 391 and 396. (The depth-hoar studies such as those cited above have not been concerned with the interaction of the gradient with single crystals per se. Nakaya (1956) did study the inverse of this phenomenon, the migration and metamorphosis of vapor inclusions within ice single crystals in temperature gradients, but the inclusions contained water vapor only, and thus the process did not involve diffusion of vapor.) Once formed, a series of equally spaced, parallel ice plates in a linear temperature gradient should thicken with time, because of the form of the dependence of vapor pressure upon temperature. Thus it is plausible that such a structure can form and be "stable", but details seem quite complicated.

\section{OTHER CRYSTAL HABITS}

While skeletal growth comprises the very great majority of the frost forms, several other forms were found, some of which have not been described previously, to our knowledge.

\section{c-axis growth}

Probably the most novel and unexpected $c$-axis growth was observed in one location in the Erebus ice cave in 1983. A vertical, flat wall was covered with skeletal hoar-frost crystals that increased uniformly in size from zero a short distance above the floor to two or three centimeters near the ceiling, about $3 \mathrm{~m}$ up. (Perhaps the flatness of this wall kept the crystal size to lower values by the competition between neighboring crystals for the vapor supply. The biggest crystals did appear generally to grow from uneven, irregular surfaces.) Between one and two meters from the floor, several tapering, pointed crystals projected several centimeters beyond the skeletal ones. One of these is shown in Figure 8. The growth is a single crystal,

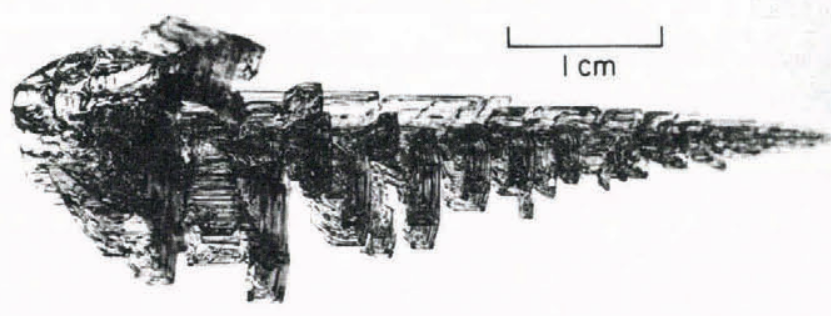

Fig. 8. c-axis "spike", Erebus Glacier tongue, 1983.

growing exactly parallel to [0001]. The tip is pointed, with six flutes coming back, and there is no trace of basal face development at the tip. The lateral growth back toward the base are the normal, skeletal forms. These crystals were very rare - there was one in each 2 or $3 \mathrm{~m}^{2}$ of wall - but they were easy to find because they grew several times faster than their skeletal neighbors. Obviously some very rare circumstance was needed to get these started and/or to keep them going, but whether it is some peculiar VLS growth, or depends upon an axial screw dislocation, or something else, is not known.

A somewhat different but more prolific $c$-axis growth form existed in the Erebus ice caves in 1982 and 1983. At one place on the ceiling of the ice cave in 1983, a patch of frost nearly two meters in diameter had the form illustrated in Figure 9: long, complexly fluted columns parallel to [0001], but not with the pointed tips of the previous example. The location was in one end of a chamber some $4 \mathrm{~m}$ high and $7 \mathrm{~m}$ long, each end of which had a low and narrow crawl space. The floor was flat, frozen sea-water. There was no

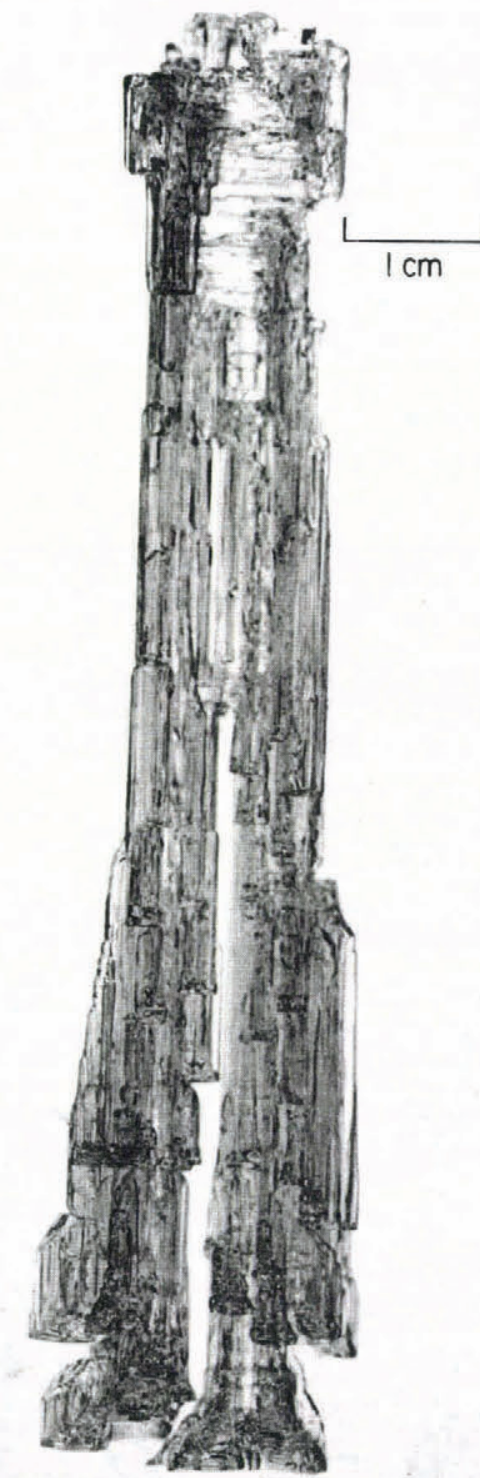

Fig. 9. Columnar frost, parallel to [0001], Erebus Glacier tongue, 1982.

obvious uniqueness about the location of the patch of the $c$-axis crystals, in terms of anything that might influence crystal growth. Another, larger example from 1982 is shown in Figure 10. The entire specimen is a single crystal, and the diagonal "fault" in the column has the correct angle to represent pyramid face development (the only example of this seen in the fluted, columnar crystals). There was one other "capped column" in the 1982 collection.

Several of these columnar crystals were sectioned perpendicular to the column axis, and examples are shown in Figure 11. The tendency toward a hexagonal hole in the middle (Fig. $11 \mathrm{~b}$ and c) is curious, but might well be expected from the idealized skeletal model of Figure 1, unless one sectioned directly through the crystal center. What is not so expected is the existence of the secondary $a$-axis branches, shown best in the right-hand example of Figure $11 \mathrm{~b}$, within a growth that extends parallel to the $c$-axis.

The South Pole tunnel also yielded large versions of the "long prism" snow crystals that have been found in very cold climates (Shimizu, 1963), and reproduced experimentally at temperatures below $-40^{\circ} \mathrm{C}$ (Kobayashi, 1965). Pyramid planes ( $11 \overline{2} 1)$ sometimes terminated these long prisms, which were as long as $2-3 \mathrm{~cm}$ and $1-2 \mathrm{~mm}$ in diameter. 


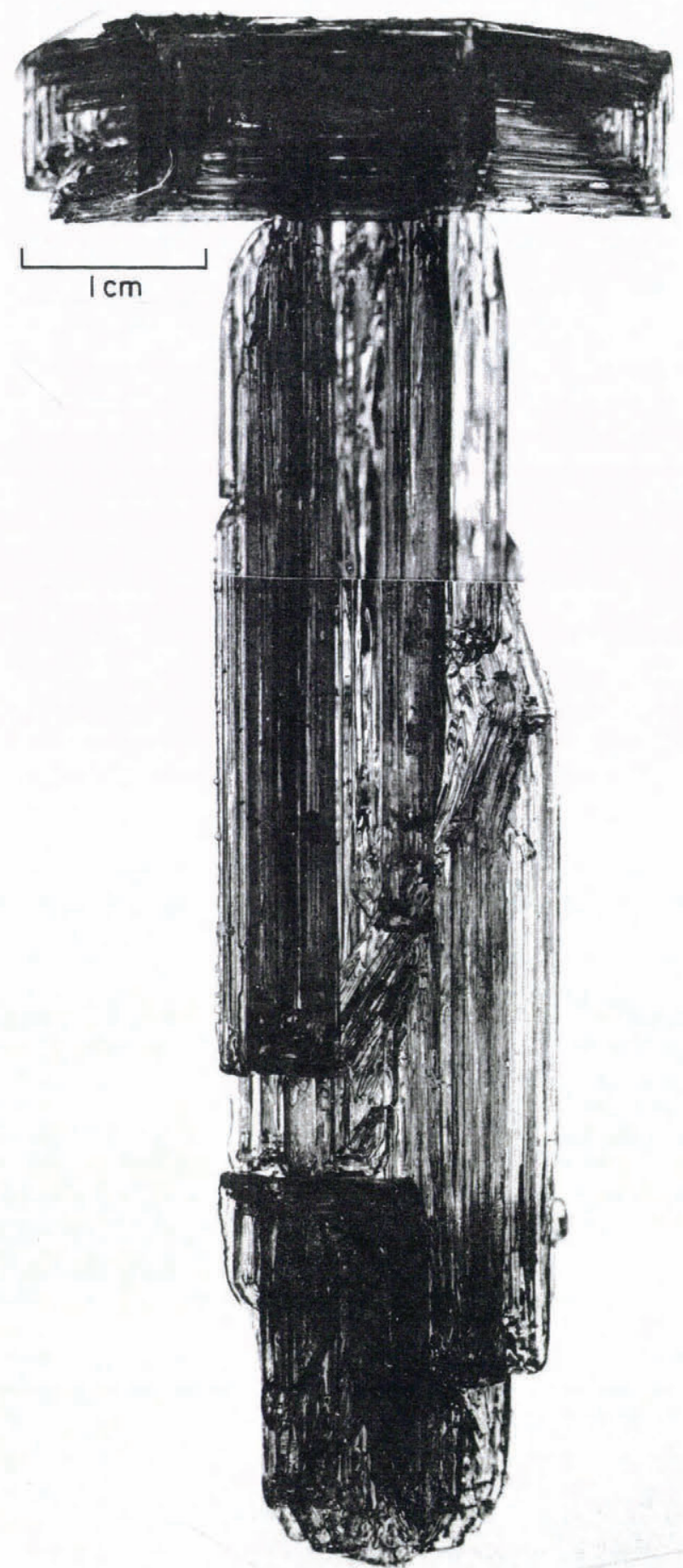

Fig. 10. Thick columnar crystal with a tabular skeletal crystal at its end, Erebus Glacier tongue, 1982.

Fast growth at a grain boundary

The last, unusual growth form is perhaps most surprising of all, and was found only in the Scott Base ice cave. It also was very rare, but also easy to find because of growing considerably faster, linearly, than its skeletal neighbors. The form is a flat sheet of spikes, rather complex-looking, and one example is shown in Figure 12. Examination using crossed polaroids and deducing [1120] orientations from the shapes of skeletal crystals on both sides of the sheets revealed that the axes of the spikes correspond to particular directions in a particular grain boundary. The bicrystal orientation involved is that found by Hallett (1964), that commonly nucleates when a supercooled water droplet impinges

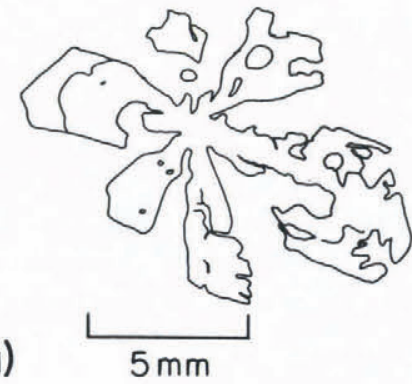

(b)
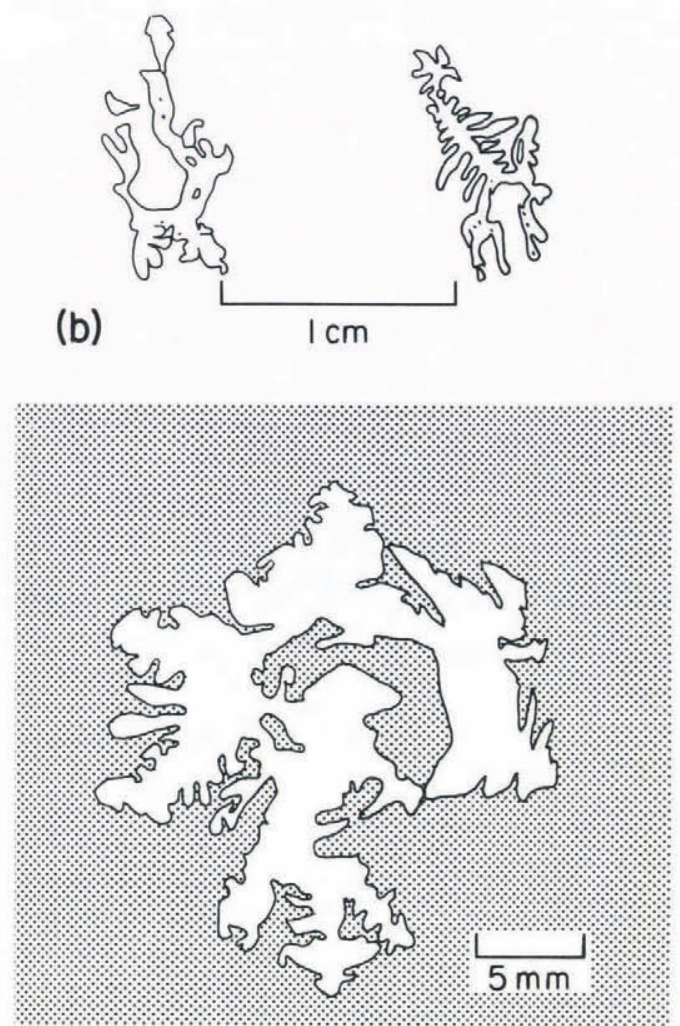

(c)

Fig. 11. Sections perpendicular to [0001], through c-axis columnar growths: (a) is through a spike, such as Figure 8; (b) are through columns, such as Figure 9; and (c) is through the stalk of Figure 10.

upon a (0001) plane of an ice crystal. In his experiment, the new crystal has its [0001] parallel to one [11 20 ] of the substrate, and one of its [1120] directions parallel to a [10י] of the substrate. At the grain boundary, (0001) of the substrate crystal coincides with $(11 \overline{2} 0)$ of the new. The orientation relations are shown in Figure 12, and explained in the caption. One of the authors (C.A.K.) has since found several examples of this type of bicrystal growth in snow at Boulder, Colorado: one especially clear example is reproduced in Figure 13. T. Kobayashi (personal communication) also has photographs of this sort of growth and pointed out published photographs, in Sato and Kikuchi (1983).

Grain boundaries coincident with an observed fastest growth direction are actually fairly common in snow crystals. Kobayashi and others (1976) showed several different examples, and in one case it has been suggested that grain-boundary dislocations can initiate new steps on the two crystal faces that form the crystal surface on either side of the grain boundary (Furukawa and Kobayashi, 1978). The conditions for this kind of growth to be found probably include (1) low enough grain-boundary energy that an interfacial groove is not expressed at the tips of the bicrystal "spikes", and (2) a 


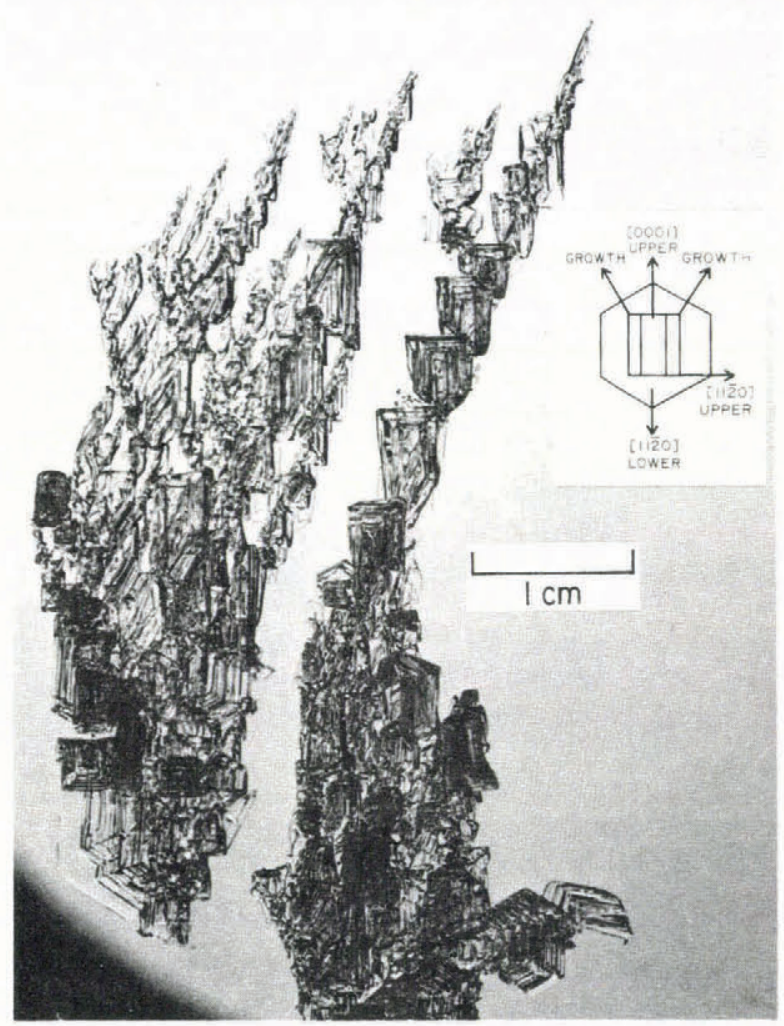

Fig. 12. Grain-boundary intergrowth, Scott Base ice cave. The orientation relations are shown. The uppermost crystal is that with its c-axis in the plane of the photograph. The crystal broke in sampling, but the two pieces are shown in correct relative position, slightly separated.

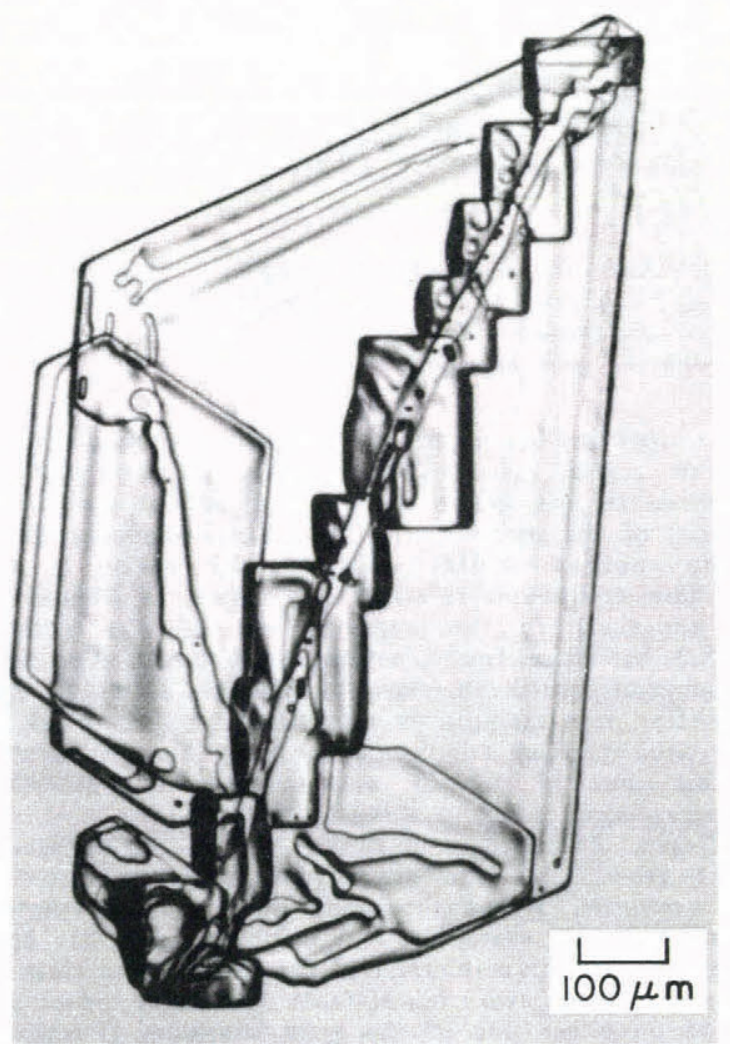

Fig. 13. Natural snow bicrystal with the same orientation relations as shown in Figure 12, except that the relations are clearer in the photograph. relative orientation of the bicrystal such that the tip, bounded by prism and basal faces of the two components, is sharper (subtends a smaller, solid angle) than the corner of a hexagonal prism, and can therefore grow faster through diffusion.

\section{CONCLUSION}

The frost forms described herein were found in a first, preliminary, field exploration - a kind of study well-suited to the Antarctic. It would be surprising if further exploration did not yield more new forms, particularly other bicrystal forms, in view of the ease of finding those described here. In fact, M. de Quervain (personal communication) has reported having observed large polycrystal frost in a deep ice pit in Greenland that had been closed for $2 \frac{1}{2}$ years. He also noted a wide variety of frost-crystal habits. Further field exploration in situations with different conditions could yield interesting results, and further field observations to look for clues to the reasons for the different growth habits could also be profitable. While final definition of the growth conditions is best done in the laboratory, careful field description and measurement may greatly narrow the range of experiments that need to be done. The new factor in the frost growth situation is, of course, the external gradient itself, its strength, and its orientation with respect to the crystal orientation. These factors have not been treated as independent variables in any of the experimental work to date, to our knowledge.

\section{ACKNOWLEDGEMENTS}

The frost observations at the South Pole were made possible by the assistnace of R. Hurtig and J. Matthews, and the encouragement of $\mathrm{Dr} \mathrm{R}$. Cameron. This work was supported by National Science Foundation (NSF) grant DPP81-16917 and by the National Center for Atmospheric Research, which is sponsored by NSF.

\section{REFERENCES}

Colbeck, S.C. 1983. Theory of metamorphism of dry snow. Journal of Geophysical Research, Vol. 88, No. C9, p. $5475-82$.

Frank, F.C. 1974. Japanese work on snow crystals. Journal of Crystal Growth, Vol. $24 / 25$, p. 3-5.

Frank, F.C. 1982. Snow crystals. Contemporary Physics, Vol. 23, No. 1, p. 3-22.

Furukawa, Y., and Kobayashi, T. 1978. On the growth mechanism of polycrystalline snow crystals with a specific grain boundary. Journal of Crystal Growth, Vol. 45, No. 1, p. 57-65.

Hallett, J. 1964. Experimental studies of the crystallization of supercooled water. Journal of the Atmospheric Sciences, Vol. 21, No. 6, p. 671-82.

Hallett, J. 1965. Field and laboratory observations of ice crystal growth from the vapor. Journal of the Atmospheric Sciences, Vol. 22, No. 1, p. 64-69.

Kobayashi, T. 1965. Vapour growth of ice crystal between -40 and $-90^{\circ} \mathrm{C}$. Journal of the Meteorological Society of Japan, Ser. 2, Vol. 43, No. 6, p. 359-67.

Kobayashi, T., and others. 1976. On twinned structures in snow crystals, by T. Kobayashi, Y. Furukawa, K. Kikuchi, and H. Vyeda. Journal of Crystal Growth, Vol. 32, No. 2, p. 233-49.

LaChapelle, E.R. 1969. Field guide to snow crystals. Seattle and London, University of Washington Press.

Levi, L., and Kobayashi, T. 1967. Ice filaments grown in a gradient of vapour pressure. Journal of the Meteorological Society of Japan, Ser. 2, Vol. 45, No. 4, p. $315-25$.

Magono, C., and Lee, C.W. 1966. Morphological classification of natural snow crystals. Journal of the Faculty of Science, Hokkaido University, Ser. 7 (Geophysics), Vol. 2, No. 4, p. 321-35. 
Mason, B.J., and others. 1963. The growth habits and surface structure of ice crystals, by B.J. Mason, G.W. Bryant, and A.P. van den Heuvel. Philosophical Magazine, Eighth Ser., Vol. 8, No. 87, p. 505-26.

Nakaya, U. 1935. On the correspondence of snow and rime crystals. Journal of the Faculty of Science. Hokkaido Imperial University, Ser. 2, Vol. 1, No. 7, p. 201-05

Nakaya, U. 1954. Snow crystals: natural and artificial. Cambridge, Mass., Harvard University Press.

Nakaya, U. 1956. Properties of single crystals of ice, revealed by internal melting. U.S. Snow, Ice and Permafrost Establishment. Research Report 13.

Nakaya, U., and Sato, I. 1935. On the artificial production of frost crystals with reference to the mechanism of formation of snow crystals. Journal of the Faculty of Science, Hokkaido Imperial University, Ser. 2, Vol. 1, No. 7, p. 206-14.

Sato, N., and Kibuchi, K. 1983. Artificial making of snow crystals of cold temperature types. Geophysical Bulletin, Hokkaido University, Vol. 42, p. 37-50.

Seligman, G. 1980. Snow structure and ski fields. Cambridge, International Glaciological Society.

Shimizu, H. 1963. "Long prism" crystals observed in the precipitation in Antarctica. Journal of the Meteorological Society of Japan, Ser. 2, Vol. 41, No. 5, p. 304-05.

Sommerfeld, R.A. 1983. A branch grain theory of temperature gradient metamorphism in snow. Journal of Geophysical Research, Vol. 88, No. C2, p. 1484-94

MS. received 20 June 1984 and in revised form 5 December 1984 